\title{
M-Commerce service systems implementation
}

\author{
Dr.Asmahan Altaher \\ Applied Science University \\ Amman - Jordan
}

\begin{abstract}
Mobile commerce supports automated banking services. However, the implementation of $\mathrm{m}$-commerce services systems has become increasingly important in today's dynamic banking environment. This research studied the relationships between technology acceptance model and $\mathrm{m}$ - commerce services. The results of the survey on 249 respondents in several Jordan banks revealed that technology acceptance model had a significant impact on m-commerce services. The results led to the recommendation that the technology acceptance model is a success model for support using new services for electronic commerce. In addition, managers play a significant role in influencing the mobile services in banks through social interaction. Managers should focus on relative advantage, usefulness, and ease of use, in order to develop the mobile commerce services implementation.
\end{abstract}

Keywords- M-commerce services; usefulness; and ease of use; social interaction.

\section{INTRODUCTION}

The growth in the mobile phone industry has accelerated in few years due to constant technological development. Recently, new forms of mobile services have made possible text messaging, web surfing, digital imaging, payments, banking, financial instrument trading and shopping [6]. With the rapid advance of telecommunication technologies, Mobile Services (MDS) is defined here as wireless access to the internet through a mobile communication network. However, mobile services are becoming increasingly important for companies and consumers because of ubiquitous, universal, easy-to-access information, and personalized exchange of information [21]. Hence, it is very important to understand how individual differences influence the use of mobile services and the behavioral adoption requirements of these services, marketers and service providers [4]. Employees may resist the change and may be a major source of concern for them. To avoid negative consequences of resistance to change, system implementers and managers must actively manage the change process and gain acceptance for new IS. The Technology Acceptance Model (TAM) suggests that employee attitudes may change if they think the new system will help them do more or better work for the same effort, and that it is easy to use [15]. TAM suggests that managers cannot get employees to use a system until they want to use it. To convince employees to use the systems, managers may need to change employees' attitudes about the system [10]. Employees attitudes may change if employees believe that the system will allow them do better work for the same amount of effort (perceived usefulness), and that it is easy to use. Training, documentation, and user support consultants are external variables that may help explain the usefulness of the system and make it easier to use; in addition, mobility model is very important to improve the efficiency of secure mobility and routing discovery [20]. TAM has many variants, for example, one variant considers subjective norms, whereas another adds attitudes toward behaviours like social influence (subjective norms), and facilitating condition (top management support). Although social influences are important, they are likely to be important only for yang workers when they are likely to start using the system. TAM assumes that technology will be accepted if people's attitudes and beliefs support its use. One way to make sure that employees' attitudes and beliefs are favourable toward the system is to have them participate in its design and implementation. When future users of the system participate in its design and implementation, they may be more willing to accept the consequences of the trade-off [10] [18]. The objective of this study is to investigate how the technology acceptance model can involve employees and allow them to understand the m- commerce services in Jordan banks. In order to address these questions, the researcher drew post-adoption components from previous studies in related fields, and conducted a large-scale survey on mature TAM in terms of how each component affected the use of m-commerce services systems. Subsequently, the theoretical background and hypotheses of this study is presented, after which a description of the research methods and data collected was presented. This was followed by an analysis of the research results. Thereafter, the conclusion was drawn.

\section{LITERATURE REVIEW}

Kim et al. [4] studied and examined factors that are most important in converting services to $\mathrm{m}$-commerce services and whether or not they differ from those that are effective in maintaining continuers. The researchers conducted an online survey to compare continuers and discontinuers empirically in terms of the relative importance of four post-adoption factors to the behavioural intention to use $\mathrm{m}$-commerce. The results show that usefulness and social influence were more important for discontinuers; and ubiquitous connectivity for continuers [17] find that the mobile phone user types are important to the mobile phone service companies, and communicative references for understanding the mobile phones. Mobile phone user types recently have become a popular subject of discussion. The researchers classify the mobile phone user types into four types: guanxi-expanding, illness-phobia, convenience-oriented and life-interrupting. The users of these mobile service companies' references for understanding the mobile phone use were adopted. However, Weber et al. [18] argued that the use of mobile technology for carrying out 
surveys is very important and are necessary actions which provide a guideline for realizing the potential of 'mobile surveys'. Essentially, the benefits are enhancements in the areas of survey quality, management and technology. The researchers recommended that the development of mobile surveys is important to create a new business model in the market. On the other hand, Xie et al. [10] present some potential security threats against m-commerce. The security attacks such as wireless-internet can seriously degrade the performance of mobile services of users; in order to promote the widespread deployment of m-commerce, the firms need to design novel and robust as well as efficient security schemes to handle these attacks. In this article, the researchers discussed some important challenges for providing ubiquitous and secure m-commerce. Finally, Lin [5] agreed that $\mathrm{m}$ commerce service is being totally satisfied with the system and their users' values; mobile technology trusting expectations were very important in the continued m-commerce service usage behaviors, and the providers might not fulfills the $\mathrm{m}$ commerce service need for consumers, but satisfied with the m-commerce service delivered. M-commerce services were introduced only a few years ago and are distinctly different from prior services and information systems because $\mathrm{m}$ commerce services systems are a type of information system; and many adoption studies [for example, Technology Acceptance Model (TAM)] have been conducted in the area. To study acceptance of the m-commerce services systems, the researcher selected four key components that have been frequently used in previous adoption studies in these areas: social influence, usefulness, ease of use and mobility model. Definitions of each component, as well as accounts of why they are pertinent to this study are as follow.

\section{PROCEDURAL DEFINITIONS}

\section{A. Social Influence:}

Social influence refers to the effect of interaction among people in their social context. Social influence helps to determine whether technologies were adopted and whether products are purchased [14]. Fisher and Price [3] found that when people purchased new products, others' opinions influenced their purchasing decisions. Social influence may also affect the use of MDS. In fact, since M-commerce is a part of the telecommunications industry - an industry specifically designed to facilitate social interactions - social influence may be an even more important factor in service choice [4] [13][20].

\section{B. Usefulness:}

Usefulness is how helpful a user feels a new product is to his or her work [10]. When the usefulness of a new product is high, the product is adopted rapidly in the market. [4] [16] have established that good quality and good function, as perceived by users, allow them to adopt a new system easily in an organizational environment. Usefulness appears to be a key factor in the adoption of M- commerce [11] [12] - especially when their usefulness differentiates them from traditional internet services. For example, subjects in one study reported using $\mathrm{m}$-commerce services only when the usefulness of their mobility really mattered [6].

\section{Ease of Use:}

Ease of use, another subjective measure, describes how easy and comfortable people find a system to learn and use. Kim et al. [4] suggested that a system is adopted quickly when a user can easily learn how to use it. Novak [8] proposed that a better system must be efficient to use. Ease of use will also be an important factor for the adoption of $\mathrm{M}$ - commerce services [1]. Providers are coming more and more to believe that ease of use is the key to retaining the greatest barrier to the adoption of M-commerce. However, compared with the resources of other systems, the resources available to make Mcommerce services easier are severely constrained [4] [17].

\section{Mobile Commerce Services:}

Mobile internet services numerously involve mobile commerce (m-commerce) services for continued and promoted business profits. Mobile technology trusting expectations were very important in the continued m-commerce service usage behaviors'; and the providers might not fulfills the $\mathrm{m}$ commerce service need of consumers, but satisfied with the mcommerce service delivered. M-commerce provides a significant value in convenience, efficiency, entertainment, mobility and location and besides extending the benefits of the web [5] [6]. Therefore, this study proposes personal values for the prediction of continuance intention. This may offer additional information or insights beyond TAM in explaining why $\mathrm{m}$-commerce services are used. M-commerce service and usage continuance intentions in terms of personal values lead to trust expectations about the m-commerce trusting and perceived performance. Most efficient factor is quick customer service. Legislation has increased customers' rights and technology and competition have increased their choice of products and providers. These changes will result in growth in users with sophisticated needs supported by [2] [9] [19].

Internet technology is rapidly changing the way personal financial services are being designed and delivered. For several years, commercial banks in Jordan have tried to introduce electronic banking (e-banking) systems to improve their operations and to reduce costs. Despite all their efforts aimed at developing better and easier e-banking systems, these systems remained largely unnoticed by the customers, and certainly were seriously underused in spite of their availability.

In this Internet age, when the customer is having access to a variety of products and services it is becoming very difficult for banks to survive. In this situation, when customer enquiries are not met easily or transactions are complicated, the customer will ask for new levels services, and only chose those institutions who are making a real effort to provide a high level of quality, fast and efficient service through all the bank's touch points, call centers, TAM, voice response systems, Internet and branches. It is considered as one of the better financial sectors in the region and generates in total close to $5 \%$ of the Gross Domestic Product (GDP). One of the weakest points in the financial sector is, with the exception of mortgage lending, the lack of long-term lending and the absence of secured loans. It is worth mentioning that the percentage of Jordanian households who own personal computer is $15.9 \%$, Internet access is $6 \%, 1,000,000$ regular telephone lines, around 1.6 million mobile telephony 
subscribers, 21 licensed Internet service providers, and more than 500,000. The banking sector is very dynamic and liberal in Jordan. Moreover, some of the commercial banks in Jordan are offering electronic services. Samples of these services are:

(1) Internet banking: Arab Bank is the first bank to launch Internet banking service. This has been started in Jordan in May 2000.

(2) Internet Shopping Card (ISC): It provides convenient and easy access to on-line shopping transactions.

(3) WAP banking: Customers can use WAP mobile phone and access their accounts.

(4) SMS banking: Customers can use a mobile phone to access their accounts.

(5) Phone bank service: This provides access to customers' accounts.

(6) On-line stock trading: Jordan Kuwait Bank (JKB) offers this service in collaboration with its affiliate (United Financial Investment).

(7) Net banker: For performing banking transactions.

(8) Mobile Banking: This service allows the customers to perform banking transactions by using a mobile.

(9) Pre-paid mobile cards: Customers can buy the mobile prepaid cards electronically.

(10) Banking via SMS: It enables the customers to receive information on their transactions through their mobile telephones [1]. The financial services industry will be used to explore $\mathrm{m}$-commerce in Jordanian banking services sector, and to investigate the effects of TAM through carrying out mcommerce in Jordanian banking sector (e-banking). The following are the research model.

\section{RESEARCH HYPOTHESES}

$\mathrm{H}_{1}$ : There is a significant positive effect between technology acceptance model and m-commerce services implementation.

$\mathrm{H}_{2}$ : There is a significant positive effect between technology acceptance model and social influences.

$\mathrm{H}_{3}$ : There is a significant positive effect between technology acceptance model and technology usefulness.

$\mathrm{H}_{4}$ : There is a significant positive effect between technology acceptance model and technology ease of use.

\section{RESEARCH MODEL}

The model depends in Technology acceptance model pearlson(2009). The researcher tries to investigate the model statistical in order find new way that can that supports involved employees and allow them to understand the $\mathrm{m}$ commerce services in Jordan banks.

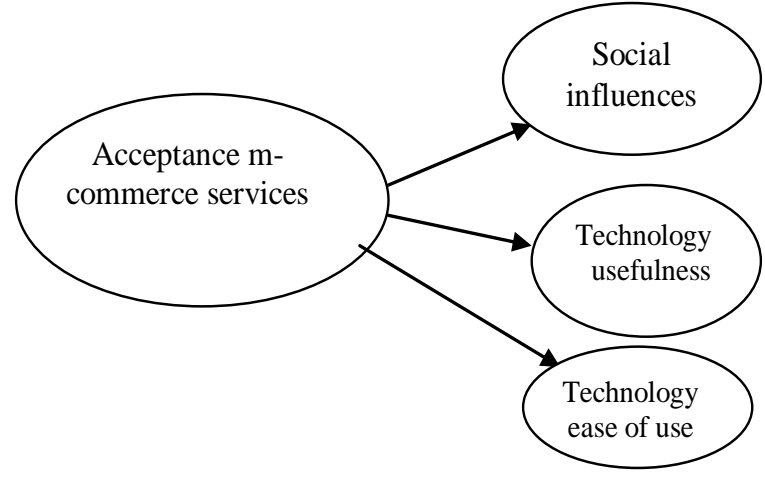

Figure.1. Research Model

Recourse: Pearlson (2009)

\section{ReSEARCH METHODOLOGY}

This research is concerned with making our problems accessible by directing it in a way that generates precise answers to precise question. The research methodology can be derived from two approaches that can be classified into two main categories: quantitative and qualitative methodology [13].

\section{A. Data Collection Methods}

The data and information will be gathered from two resources, namely: primary and secondary resources.

i) Primary resources: Individual focus groups, and a panel of respondents set up by the researcher whose opinions may be sought on specific issues from time to time are examples of primary data sources [1]. Data can also be culled from administering questionnaire. Questionnaires are an efficient data collection mechanism when the researcher knows exactly what is required and how to measure the variable of interest [22]. In this study, questionnaires were sent to respondents in the senior level, and top managers in management.

ii) Secondary resources: Data can also be obtained from secondary sources, as the scientific (Books, articles, etc) sources concerned with the study.

\section{B. Initial Design And Development Of The Survey Instrument:}

Many criteria should be considered when designing a questionnaire survey [22]. On the choice of wording, questionnaire design and layout were adopted. Items in the questionnaire were designed to being simple, clear, short, technical, accurate, bias free, and at an appropriate reading level [1] [22] were taken into account when designing the questionnaire, such as those that started with a brief description on how to answer the questionnaire. An initial draft of questionnaire was developed based on an extensive literature review and existing measures.

\section{Decisions Related To Population And Sample Selections:}

The banks market is huge and has been growing rapidly in recent years. Banks can use all of the e-services. 
However, many large banks receive additional e-services, the banks was seen as an appropriate business environment that is particularly suitable to test for the research model and the determinations of the $\mathrm{m}$-commerce implementations in ebanking. Jordan has sixteen banks, Arab banks controlling the local market and, account for more than $40-50 \%$ of the country's total production. Sekaran [22] defined research population as any exactly defined set of people, or collection of items, that is under investigation. In the light of this definition, the research population, and the actual sample are identified as the four banks that dominate the local market and account for more than $75 \%$ of the country's total production. These are Arab Bank, The Housing Bank for Trading Finance, Jordan Bank, and Standard Chartered Bank.

A questionnaire was sent to respondents in operation, middle and top management. A stratified random sampling method will be used, as it is the most convenient, and the most applicable in the Jordanian context.

The unit of analysis in this study is managers working in Jordan banks. 200 questionnaires were sent to 320 populations; 263 were returned, and 14 questionnaires were ignored because they were not returned. The overall response rate for this study is $82 \%$, while the response rate actually used is $78 \%$.

This is regarded as relatively high, since the respondents are managers who are supposed to be too busy to answer questionnaires. However, it is found that the sample is sufficient to represent the regression analysis conducted.

\section{Operationalisation And Measurement Strategy Of The Model Variables:}

The measures of model variables in this study were analyzed using statistical procedures starting with internal consistency test and establishing constructs reliability. Statistical procedures are common among many researchers such as Malhotra et al. [23].

1) Internal consistency to assess the reliability of the scale using Cronbach's alpha.

2) Developing a structural model based on the composite measures to linking the hypothesized model's constructs.

3) Descriptive analysis of the mean and standard deviation of the investigated hypotheses.

\section{E. Internal Reliability}

The internal consistency measures and Cronbach's alpha are obtained in order to assess the reliability of the measurement instruments. Table 1 shows the Cronbach's alpha value for each scale. It is clear that Cronbach alpha is acceptable statistically and managerially because $\alpha$ values are greater than the accepted $0.65 \%$.

TABLE 1. Cronbach alpha

\begin{tabular}{|l|c|}
\hline Variable & Cronbach's alpha \\
\hline Implementation M-commerce & 0.756 \\
\hline Social influence & 0.732 \\
\hline Usefulness & 0.678 \\
\hline Ease of use & 0.692 \\
\hline
\end{tabular}

\section{DESCRIPTIVE STATISTICS}

Descriptive statistics such as means frequencies, and standard deviation, were used to identify the major characteristics of respondents in terms of their gender, age, educational level and working experience.

TABle 2. Descriptive Statistics

\begin{tabular}{|c|c|c|}
\hline Demographic object & Valid item & \% \\
\hline \multirow{3}{*}{ Gender } & Male & 64.7 \\
\cline { 2 - 3 } & Female & 35.3 \\
\hline \multirow{3}{*}{ Employee age (years) } & $20-30$ & 41.0 \\
\cline { 2 - 3 } & $30-40$ & 35.38 \\
\cline { 2 - 3 } & $40-50$ & 15.17 \\
\hline \multirow{3}{*}{ Education level } & Above 50 & 8.45 \\
\cline { 2 - 3 } & College degree & 1.5 \\
\cline { 2 - 3 } & Bachelor degree & 88.2 \\
\hline \multirow{3}{*}{ Work experience (years) } & Postgraduate degree & 10.3 \\
\cline { 2 - 3 } & Less than 6 & 29.0 \\
\cline { 2 - 3 } & From 1 - 2 & 25.0 \\
\cline { 2 - 3 } & $5-10$ & 25.63 \\
\hline
\end{tabular}

\section{RESULTS}

This study attempts to identify the technology acceptance model effects on implementation of mobile commerce ebanking services. The statistical results indicated the TAM effects of mobile services implementation. All analyses were conducted with SPSS. Frequency and percentage were used to describe the samples of the study and multiple regression analysis was conducted to test the research hypotheses.

\section{A. Measuring The Effect Between The Independent Variable And Dependent Variable Simple Regression}

Most of the respondents agreed that there is a good and close relationship between TAM factor and mobile services implementations (Mean=3, 69; $\mathrm{SD}=0.98$ ). The result of the regression analysis shows that there is a significant positive effect at the function level $(\alpha \leq 0.01)$ which means that there is a relationship between TAM and mobile commerce implementation for the independent variables with a variance of $47.4 \%$; thus, Hypothesis 1 was supported.

\section{B. The Effect Between Social Influence And Mobile Commerce Implementation}

From the results in Table 3 which relate to correlation between the independent variable social influence and the dependent variable mobile commerce implementation, a positive and significant effect can be found at function level ( $\alpha$ $\leq 0.01)$ which supports the hypothesis $\left(\mathrm{H}_{2}\right)$, where $(\mathrm{r}=0.499)$.

Based on the results in Table 3 which represent simple regression analysis, Simple regression was used to test the above hypothesis, and it was found that the calculated $t$ (8.112) is significant at $(\mathrm{p}<0.001)$ level, which means that there is a relationship between social influence and mobile commerce implementation. It was observed that the variance was $41.1 \%$, as such, Hypothesis 2 was supported. 
TABLE 3. The EFFEct Between Social InFLuence AND MobiLe COMMERCE IMPLEMENTATION

\begin{tabular}{|l|c|c|c|}
\hline Variable & Beta & Sig \\
\hline $\begin{array}{l}\text { Social influence and mobile commerce } \\
\text { implementation }\end{array}$ & 0.499 & 0.000 \\
\hline
\end{tabular}

\section{Effect Between Usefulness And Mobile Commerce Implementation}

Based on the results in Table 4 which relate to correlation relationship between the independent variable usefulness and the dependent variable mobile commerce implementation, a positive and significant effect can be found at function level $(\alpha$ $\leq 0.01)$ which supports the hypothesis $\left(\mathrm{H}_{3}\right)$. Based on the results in Table 4 which represent simple regression analysis, simple regression was used to test the above hypothesis, and it was found that the calculated $\mathrm{t}(89.932)$ is significant at $(0.01)$ level, which means that there is a relationship between them. A significant effect can be noticed at function level $(\alpha \leq 0.01)$ to the independent variable usefulness in the dependent variable mobile commerce implementation. The variance was observed as $61.7 \%$. Thus, hypothesis 3 is supported.

\section{TABLE 4. The EFFect Usefulness AND Mobile CoMmerce} IMPLEMENTATION

\begin{tabular}{|l|l|l|}
\hline Variable & Beta & Sig \\
\hline Usefulness and mobile commerce implementation & 0.393 & 0.000 \\
\hline
\end{tabular}

\section{Effect between ease of use and mobile commerce implementation}

Based on the results in Table 5 which relate to correlation relationship between the independent variable services, ease of use and the dependent variable mobile commerce implementation, a positive and significant effect can be found at function level $(\alpha \leq 0.01)$, which supports the hypothesis $\left(\mathrm{H}_{4}\right)$ (Table 5). Simple regression was used to test the above hypothesis and it was found that the calculated $t$ (7.641) is significant at (0.01) level; a significant effect can be found at function level $(\alpha \leq 0.01)$. The variance is (0.681). Thus, hypothesis 4 is supported partially.

TABLE 5. The Effect between Ease of Use and Mobile Commerce Implementation

\begin{tabular}{|l|l|l|}
\hline Variable & Beta & Sig \\
\hline Ease of use and mobile commerce implementation & 0.329 & 0.000 \\
\hline
\end{tabular}

\section{CONCLUSION}

The researcher investigated the Technology acceptance model statistical in order find new way that can that supports involved employees and allows them to understand the $\mathrm{m}$ commerce services in Jordan banks. The researcher argued that developing countries have to apply the technology acceptance model in order to help employees accept the new types of e-services.

A technology acceptance model is a success model for support using new services for electronic commerce. Social influence plays a significant role in influencing the mobile services in banks. Managers should focus on relative advantage of the usefulness and ease of use, in order to develop the mobile commerce implementation. Banks should introduce $\mathrm{m}$-commerce service to revise their customer service need. In addition, banks should focus on service model and its applications. Managers should be demanding and challenging, so long as they are consistent in their treatment to usefulness of mobile commerce services. Finally, bank managers should make continuous evaluation and honest dialogue about the ease of use of mobile commerce services.

However, regardless of their limitations, it is useful to continue analysing the new types of e-services through the technology acceptance model. By doing so, first it is expected that deeper insights would be gained into the banking industry itself and its evolution over time. Secondly, this study hopes to develop the evaluation framework that was used, which can be transferred to other types of industries.

\section{ACKNOWLEDGEMENT}

The author is grateful to the Applied Science Private University, Amman, Jordan, for the financial support granted to cover the publication fee of this research article.

\section{REFERENCES}

[1] Alawneh, A., and Hattab, E. (2008b). "E-business Value Creation Jordanian Banking Services Industry: An Empirical Analysis of Key Factors". International Arab Conference on e- technology. Arab Open University, Amman-Jordan. October 15-10, 2010.

[2] Deng, H., Li, W. and Agrawal, D.P. (2002a) 'Routing security in Ad Hoc networks', IEEE Communications Magazine, Special Topics on Security in Telecommunication Networks, October 2002, Vol. 40, No. 10, pp.70-75.

[3] Fisher, R.J. and Price, L.L. (1992) 'An investigation into the social context of early adoption behavior', Journal of Consumer Research, Vol. 19, pp.477-486.

[4] Kim, H., Lee, I. and Kim, J. (2008) 'Maintaining continuers vs. converting discontinuers: relative importance of post-adoption factors for mobile data services', Int. J. Mobile Communications, Vol. 6, No. 1, pp.108-132.

[5] Lin, Y-M. and Shih, D-H. (2008) 'Deconstructing mobile commerce service with continuance intention', Int. J. Mobile Communications, Vol. 6, No. 1, pp.67-87.

[6] Liu, C-C. (2008) 'Mobile phone user types by Q methodology: an exploratory research', Int. J. Mobile Communications, Vol. 6, No. 1, pp.16-31.

[7] Miranda, F.J. Cortés, R and Barriuso, C. (2006) "Quantitative Evaluation of e-Banking Web Sites: an Empirical Study of Spanish Banks" The Electronic Journal Information Systems Evaluation Volume 9 Issue 2, pp 73 - 82, available online at www.ejise.com

[8] Novak, T. P., and Hoffman, D. (1997) "Modeling the Structure of Flow Experience Among Web Users," Vanderbilt University.

[9] Orr, B. (2004) E-Banking job one: Give customers a good ride. ABA Banking Journal, Vol. 96, Iss. 5, pp 56-57.

[10] pearlson, C, Saunders ,S (2009) strategic management information systems, Forth edition, Johan Wiley \& sons, INC.

[11] Scornavacca, E., Prasad, M. and Lehmann, H. (2006) 'Exploring the organizational impact and perceived benefits of wireless Personal Digital Assistants in restaurants', Int. J. Mobile Communications, Vol. 4, pp.558-567.

[12] Selz, D. and Schubert, P. (1997): "Web assessment: A model for the evaluation and the assessment of successful electronic commerce applications". Electronic Markets, vol 7, n 3, pp.46-48.

[13] Stuart, J.B. and Sid, L.H. (2003) 'Rising sun: iMode and the wireless internet', Communications of the ACM, Vol. 46, pp.78-84.

[14] [Venkatesh, V., Ramesh, V. and Massey, A.P. (2003) 'Understanding usability in mobile commerce', Communications of the ACM, Vol. 46, pp.53-56.

[15] venkatesh,,V., Morreis,MG., Davis, F.D. (2003) User acceptance of information technology :Toward a unifeied view. MIS Quarterly, 27(3), 435- 478. 
[16] zMiranda, F.J. Cortés, R and Barriuso, C. (2006) "Quantitative Evaluation of e-Banking Web Sites: an Empirical Study of Spanish Banks" The Electronic Journal Information Systems Evaluation Volume 9 Issue 2, pp 73 - 82, available online at www.ejise.

[17] Watson, R.T., Pitt, L.F., Berthon, P. and Zinkhan, G.M. (2002) 'Ucommerce: expanding the universe of marketing', Journal of the Academy of Marketing Sciences, Vol. 30, pp.333-347.

[18] Weber, M., Denk, M., Oberecker, K., Strauss, C. and Stummer, C. (2008) 'Panel surveys go mobile', Int. J. Mobile Communications, Vol. 6, No. 1, pp.88-107.

[19] Xie, B., Kumar, A. and Agrawal, D.P. (2008) 'enabling multi-service on $3 \mathrm{G}$ and beyond: challenges and future directions', IEEE Wireless Communication Magazine.
[20] Xie, B., Kumar, A., Zhao, D., Reddy, R. and He, B. (2010) 'On secure communication in integrated heterogeneous wireless networks', Int. J. Information Technology, Communications and Convergence, Vol. 1, No. 1, pp.4-23.

[21] Wells, N., and J. Wolfers, "Finance with a personalized touch," Communication of the ACM, Vol. 43, No. 8: 30-34, 2000.

[22] Sekaran ,U. (1992 ). Research Methods for Business: A skill Building Approach, Second Edtion, alynow university press, USA p (285-301).

[23] Malhotra, K.and Briks D., (2000). Marketing Research: An Applied Approach, European Edition, prentice - Hall. 